\title{
Diesel exposure and mortality among railway workers: results of a pilot study
}

\author{
M B SCHENKER, ' T SMITH, ${ }^{2}$ A MUÑOZ,' SUSAN WOSKIE, ${ }^{2}$ AND F E SPEIZER ${ }^{12}$ \\ From the Channing Laboratory, ' Department of Medicine, Brigham and Women's Hospital and Harvard \\ Medical School, and the Department of Environmental Sciences and Physiology, ${ }^{2}$ Harvard School of Public \\ Health, Boston, MA, USA
}

ABSTRACT A pilot study of the mortality of railway workers was undertaken to evaluate the feasibility of studying the association of exposure to diesel exhaust and cause specific mortality. The cohort consisted of 2519 white male subjects aged 45-64 with at least 10 years of railway service by 1967 . Subjects were selected on the basis of job classification, and cause specific mortality was ascertained for subjects who died $(n=501)$ up to 1979 . The total follow up period was $28.4(\times 1000)$ person-years. The standardised mortality ratio (SMR) for the cohort, based on United States national rates, was 87 (95\% confidence limits 80,95$)$, and there were no significant differences from expected number of deaths for any specific neoplasm. The directly standardised rate ratio for respiratory cancer among diesel exposed subjects relative to unexposed subjects was $1 \cdot 42 \pm 0.50(\overline{\mathrm{x}} \pm \mathrm{SE})$. A proportional hazards model was consistent with the findings of the standardised rate ratio, but in neither analysis was the increased risk of respiratory cancer in diesel exposed subjects statistically significant.

There has recently been increased concern about the potential adverse health effects of diesel exhaust. ${ }^{1-4}$ Diesel engines have greater fuel economy than petrol engines and are being used increasingly in many light duty vehicles. The Environmental Protection Agency has estimated that by $1995,20 \%$ of the United States automobile fleet will be powered by diesel engines, and these vehicles will release 60000 tons or more of diesel exhaust particles a year into the ambient environment. ${ }^{5}$ There is also concern about the health effects in occupational groups such as bus and train workers and some underground miners with exposure to diesel exhaust..$^{6-8}$

The major difference in the exhaust characteristics of diesel and gasoline engines is that diesel exhaust contains 50 to 100 times as much particulate matter. ${ }^{4}$ Particulate extracts from diesel exhaust have been known for several years to contain carcinogenic polycyclic aromatic hydrocarbons and have been shown to be mutagenic in several short term in vitro assay systems. ${ }^{139-11}$ Concern also exists about diesel exhaust because most of the particles are submicron in size and may be deposited deep in the lung. Mutagenic compounds adhere to

Received 28 February 1983

Accepted 9 May 1983 the central carbonaceous core of diesel exhaust particulates and are deposited in the respirable areas of the lung where they may cause lung cancer or other diseases. ${ }^{12}$

Despite extensive in vitro testing of diesel exhaust particles, there have been few epidemiological studies of diesel exposed populations.' We have designed a retrospective cohort study of United States railway workers to evaluate the possible carcinogenic effect of diesel exhaust exposure. To detect a relative risk of $1.5(\alpha=0.05, \beta=0.20)$, a cohort of 25000 workers was calculated to be necessary. ${ }^{8}$ The need for greater statistical power increased the sample size estimate to over 50000 subjects. The pilot study reported here was completed to test the feasibility of a larger cohort study. We have begun a retrospective cohort study of 60000 workers and a case-control study of incident deaths in railway workers based on the results of this pilot study. These current studies will address the issues with greater statistical power.

\section{Methods}

POPULATION

All data on work histories and mortality were obtained from the United States Railroad Retire- 
ment Board in Chicago which maintains records on over six million current, retired, and dead United States railway workers. The cohort of the pilot study consisted of male workers who, in 1967, were aged between 45 and 64 , were working, and had had at least 10 years of railway service.

The cohort was selected from four general occupational groups in 1967 that included known or suspected diesel expoşed occupations and control occupations of comparable socioeconomic status. These groups were:

(1) Station agents, telegraphers, clerks, and other office employees.

(2) Engineers and conductors.

(3) Firemen, brakemen, switchmen, and hostlers.

(4) Shop and stores employees.

\section{FOLLOW UP}

Death certificates were requested for all subjects reported by the Railroad Retirement Board to have died in the period 1 January 1967 to 31 December 1979. About a quarter of the death certificates were obtained from the Railroad Retirement Board; the remainder were requested from the appropriate state boards of health. Since the Railroad Retirement Board provides a death benefit for all employees with at least 10 years' service, these records were considered complete for death ascertainment. Employees who have worked for at least 10 years in the railway industry and subsequently for two years or more in another industry receive benefits from the Social Security Administration. The prevalence of such transfers is unknown, but is estimated by the Railroad Retirement Board to be less than 2-3\%. Because of constraints of time and money, these potential deaths were not followed up.

The underlying cause of death was coded from the death certificate by a trained nosologist according to the International Classification of Diseases, 8th revision (ICD-8). All subjects not reported to have died before 31 December 1979 were assumed to be alive. Subjects reported to have died and for whom cause of death was not determined were assumed to have

Table 1 Representative examples of job classification in the four categories of exposure to diesel. Jobs listed are selected from over 150 Interstate Commerce Commission (ICC) job classifications

\begin{tabular}{ll}
\hline Unexposed: & $\begin{array}{l}\text { Clerks, ticket agents, messengers, claim agents, } \\
\text { bridge and building workers, gang workers and } \\
\text { foremen, signalmen, inspectors, dispatchers }\end{array}$ \\
Low diesel: & $\begin{array}{l}\text { Hostlers, conductors, brakemen, flagmen, } \\
\text { engineers, firemen }\end{array}$ \\
High diesel: & $\begin{array}{l}\text { Enginehouse foremen, labourers, tradesworkers } \\
\text { Motor vehicle operators, portable equipment } \\
\text { Operators, carmen, dock labourers, boat } \\
\text { workers, truck platform workers }\end{array}$ \\
\hline
\end{tabular}

died due to unknown cause on the date reported by the Railroad Retirement Board.

The initial cohort consisted of 6405 subjects of whom 1851 had died by the end of the follow up period. A one third sample of subjects was selected as the pilot study cohort, resulting in 2091 live and 575 dead subjects. Mortality analysis was conducted in white men only on a total of 2519 subjects (1987 alive, 532 dead). Death certificates were obtained for $501(94.2 \%)$ of these cases. There was no significant difference in age, year started work, years worked, year or age at death, or diesel exposure in 1959 between subjects for whom we did and did not obtain death certificates.

\section{DIESEL EXPOSURE}

Diesel exhaust exposure categories were estimated for about 150 railway job classifications. ${ }^{1314}$ The determination of exposure was based on a review of previous studies of the railways ${ }^{15} 16$ and on data from industrial hygiene measurements of diesel exposure in the railway being made as part of the larger epidemiological study. These measurements were used in part for the stratification of jobs into diesel exposure categories.

Three strata of diesel exposure were defined (table 1). Unexposed jobs were those with no known occupational exposure to diesel exhaust. Low diesel exposure jobs generally included train operating personnel, and high diesel exposure jobs contained those who worked in round houses or engine repair sheds. A fourth category of undefined jobs consisted of occupations with possible intermittent exposure to exhaust.

The job category for each year's work was available for each subject from 1959 until death, retirement, or the end of the follow up period. Diesel exposure category for this analysis was based on job classification in 1959. Exposure data in 1959 were missing for 19 subjects, and job category in 1967 was used for those cases. Diesel exposed jobs comprised $70.3 \%$ of the cohort in 1959 , and unexposed jobs represented $27 \%$ of the cohort; the remaining $2.7 \%$ were in undefined jobs.

MORTALITY ANALYSIS

Standardised mortality ratios (SMRs) were calculated for the entire cohort and for the subjects exposed and unexposed to diesel. Results are reported as the ratio of observed to expected deaths. Expected deaths were obtained by multiplying the person-years of survival in five year age-time groups by the age-time cause specific mortality rates for United States white men. ${ }^{17}$ Time-specific five year interval rates were used for 1965-9 and 1970-4; the 1970-4 rates were used for 1975-9. For the SMR 
analysis, subjects with either "low" or "high" exposure were grouped together, and subjects in the "undefined" category were excluded from the analysis. Directly standardised rate ratios were computed for deaths from respiratory cancer in the subjects exposed and unexposed to diesel. Rates were based on the overall five year age-time person-year distribution of all subjects in the study. This method avoids potential sources of error from comparing SMRs in two populations.

Survival curves were estimated by the KaplanMeier method ${ }^{18}$ and regression analysis was carried out using the proportional hazards model. ${ }^{19}$ The regression analysis used the BMDP programme for life table and survival function; ${ }^{20}$ the procedure was used only for respiratory cancer mortality. Survival times for all deaths not due to respiratory cancer and all subjects alive at the end of the follow up period were censored. Diesel exposure, based on 1959 job classifications, was entered on a continuous scale as follows: unexposed $=0$, undefined $=0 \cdot 5$, low diesel $=1 \cdot 0$, and high diesel $=2 \cdot 5$. The relative weightings were based on the approximate ratios of respirable particulates observed in the preliminary exposure measurements on the job groups. Other covariates tested were age in 1967 (years) and year the subject started work (before or after 1945).

\section{Results}

In 1959 there were 1770 white men in diesel exposed jobs and 679 in unexposed jobs. They contributed $19.9(\times 1000)$ and $7.6(\times 1000)$ personyears of follow up respectively (table 2). In 195970 subjects were in "undefined" diesel exposure categories. The proportions of workers with various levels of exposure to diesel exhaust were similar across categories of age groups in the study cohort (fig 1), although a small increase in the proportion of unexposed workers was present in the oldest age group (59-64 years old in 1967). The proportions of workers in diesel exposure categories grouped by

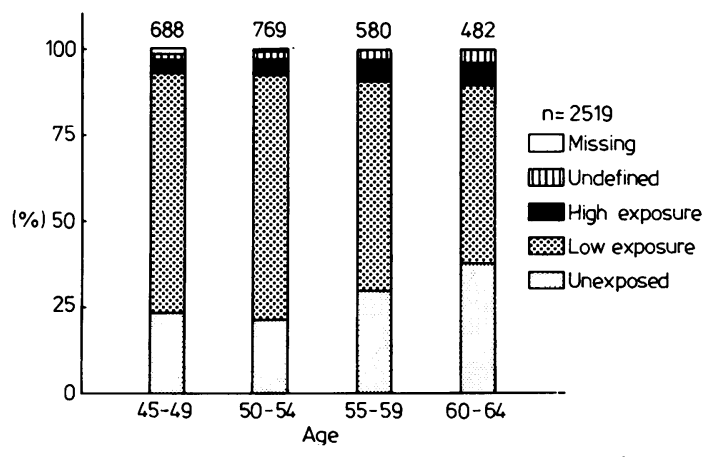

Fig 1 Distribution of age groups in 1967 by diesel exposure determined from job classification in 1959. Number of subjects in each age group is shown above the respective histogram bar.

the year a subject started work on the railways were generally similar (fig 2): $77 \%$ of the subjects in the study cohort began work before 1945 .

Job histories are stable in the railway industry. ${ }^{21}$ In our own data $94 \%$ of diesel exposed and $91 \%$ of unexposed workers in 1959 still remained in their respective exposure categories in 1967. Of the 1758 diesel exposed subjects in $1959,5 \cdot 6 \%$ were in unexposed jobs in 1967 . Changes to an exposed job by 1967 occurred for $8.3 \%$ of the 672 white male workers who were in an unexposed job in 1959.

Standardised mortality ratios (SMRs) for all causes were initially calculated for the entire cohort (table 3). No association was present for SMR and total years worked or year of death, but a small trend of decreasing SMR with older age at death was noted. Several of the categories in this table are correlated-for example, the categories of year started work would be correlated with total number of years worked. A subject who began work after 1950 could not have more than 30 years of work experience.

The number of observed cases of cause specific mortality was generally less than the expected

Table 2 Follow up experience of cohort. Diesel exposed subjects include low and high exposure

\begin{tabular}{|c|c|c|c|c|}
\hline \multirow[t]{2}{*}{ Initial sample } & \multirow{2}{*}{$\begin{array}{l}\text { Total } \\
2662\end{array}$} & \multicolumn{3}{|c|}{ Diesel exposure (1959) } \\
\hline & & $\begin{array}{l}Y^{*}{ }^{*} \\
1843(69 \cdot 2)\end{array}$ & $\begin{array}{l}\mathrm{No} \\
742\end{array}$ & $\begin{array}{l}\text { Undefined } \\
77(2 \cdot 9)\end{array}$ \\
\hline $\begin{array}{l}\text { White man: } \\
\text { Alive (1979) } \\
\text { Dead (1979) }\end{array}$ & $\begin{array}{r}2519 \\
1987 \\
532\end{array}$ & $\begin{array}{r}1770(70 \cdot 3) \\
1399 \\
371(69 \cdot 7)\end{array}$ & $\begin{array}{l}679(27 \cdot 0) \\
529 \\
150(28 \cdot 2)\end{array}$ & $\begin{array}{l}70(2 \cdot 7) \\
59 \\
11(2 \cdot 1)\end{array}$ \\
\hline $\begin{array}{l}\text { Person-years }(\times 1000) \text { : } \\
\text { Average age, 1967 } \\
\text { Average age, death } \\
\text { Average year, death }\end{array}$ & $\begin{array}{r}28 \cdot 4 \\
53 \cdot 2 \\
61 \cdot 5 \\
1973 \cdot 7\end{array}$ & $\begin{array}{r}19 \cdot 9 \\
52.7 \\
61 \cdot 2 \\
1973 \cdot 6\end{array}$ & $\begin{array}{r}7 \cdot 6 \\
54 \cdot 2 \\
62 \cdot 4 \\
1973 \cdot 9\end{array}$ & $0 \cdot 9$ \\
\hline
\end{tabular}

${ }^{*}$ Low and high diesel exposure. 


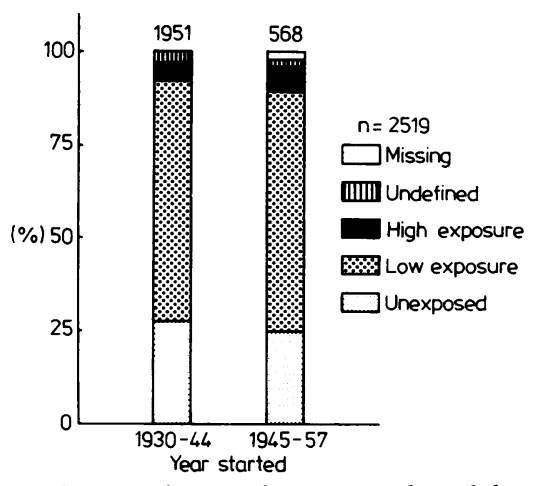

Fig 2 Distribution of year subjects started work by diesel exposure based on 1959 job classification.

number of cases based on United States national rates (table 4). SMRs were significantly less than expected for all causes (87), all circulatory diseases (78), and all respiratory diseases (54). The number

Table 3 Ratio of observed to expected deaths (and observed deaths) in cohort according to specific age and work characteristics. Ratios times 100 equal SMRs

\begin{tabular}{|c|c|c|c|}
\hline Characteristic & Category (years) & Obs/Exp & $(O b s)$ \\
\hline Age started work & $\begin{array}{l}<25 \\
25-35 \\
>35\end{array}$ & $\begin{array}{l}1.14 \\
0.84 \\
0.81\end{array}$ & $\begin{array}{r}(93) \\
(341) \\
(98)\end{array}$ \\
\hline Year started work & $\begin{array}{c}<1940 \\
1940-9 \\
\geqslant 1950\end{array}$ & $\begin{array}{l}0.82 \\
0.88 \\
1.14\end{array}$ & $\left.\begin{array}{r}157) \\
337 \\
(38\end{array}\right)$ \\
\hline Years worked & $\begin{array}{rl} & 10-19 \\
20-29 & 30\end{array}$ & $\begin{array}{l}0.83 \\
0.84 \\
0.91\end{array}$ & $\left.\begin{array}{r}(22) \\
(256) \\
254\end{array}\right)$ \\
\hline Age at death & $\begin{array}{r}45-54 \\
55-64 \\
65-74\end{array}$ & $\begin{array}{l}1.09 \\
0.94 \\
0.71\end{array}$ & $\begin{array}{r}(87) \\
(284) \\
161\end{array}$ \\
\hline Year of death & $\begin{array}{l}1965-9 \\
1970-4 \\
1975-9\end{array}$ & $\begin{array}{l}0.86 \\
0.97 \\
0.79\end{array}$ & $\begin{array}{r}(98) \\
(228) \\
(206)\end{array}$ \\
\hline
\end{tabular}

of observed cases of specific neoplasms was not consistently less than the expected number, but the expected number of many cancers was small, and none of the $95 \%$ confidence limits for cancers excluded 100 or no difference from expected. The SMRs for lung cancer $($ ICD code $=162)$ and all respiratory system cancers $(I C D=161-163)$ were similar ( 82 and 85 , respectively) and subsequent analyses were performed on respiratory cancer only.

\section{RESPIRATORY CANCER}

The number of observed cases of respiratory cancer was less than the number expected for all age and time specific categories among the subjects not exposed to diesel exhaust, and for most categories among those exposed to diesel (table 5). None of the SMRs in table 5 differed significantly from the number expected based on age and calendar time specific United States rates.

The rates for respiratory cancer were also calculated in subjects exposed and unexposed to diesel, directly standardised to the age and calendar time distribution of the entire cohort (table 6). Among subjects exposed to diesel in 1959, the rate of respiratory cancer $(\times 1000$ person-years $)$ was 1.877 \pm 0.319 (SE); for the unexposed subjects the rate was $1.325 \pm 0.407$ (SE). Comparing these two mutually standardised rates yields a rate ratio for respiratory cancer in diesel exposed subjects relative to unexposed subjects of $1.42 \pm 0.50 \quad(95 \%$ confidence limit $0.45,2.39$ ) - that is, the risk of respiratory cancer was $42 \%$ greater in the subjects exposed to diesel than in the subjects not exposed to diesel exhaust, but the increase was not statistically significant.

Life table analysis for respiratory cancer also showed a higher risk of death from respiratory cancer in workers exposed to diesel (fig 3). The

Table 4 Observed to expected ratios for selected causes of death (ICD 8) for all workers in the cohort. Expected deaths based on age, sex, race, calendar time specific US national rates

\begin{tabular}{|c|c|c|c|c|}
\hline & Observed & Expected & Obs/Exp & $95 \% C L$ \\
\hline $\begin{array}{l}\text { All causes of death } \\
\text { All malignant neoplasms }(140-208) \\
\text { Cancer of oesophagus }(150) \\
\text { Cancer of stomach }(151) \\
\text { Cancer of large bowel, rectum }(153,154) \\
\text { Cancer of respiratory system }(161-163) \\
\text { Cancer of lung }(162) \\
\text { Cancer of bladder }(188) \\
\text { Cancer of kidney }(189) \\
\text { Cancer of brain, central nervous system }(191,192) \\
\text { Cancer of thyroid }(193) \\
\text { Lymphatic cancer }(200,208) \\
\text { Leukaemia (204) } \\
\text { All circulatory diseases }(390-458) \\
\text { All respiratory diseases }(460-519) \\
\text { All diseases of digestive system (520-579) } \\
\text { Accidents, poisoning, drowning (800-999) } \\
\text { Deaths without certificates }(\% \text { total deaths) }\end{array}$ & $\begin{array}{r}532 \\
129 \\
4 \\
4 \\
15 \\
47 \\
43 \\
3 \\
6 \\
5 \\
2 \\
6 \\
7 \\
252 \\
21 \\
23 \\
30 \\
31\end{array}$ & $\begin{array}{r}610 \cdot 4 \\
141 \cdot 0 \\
3 \cdot 6 \\
6 \cdot 0 \\
16 \cdot 2 \\
55 \cdot 1 \\
52 \cdot 3 \\
4 \cdot 0 \\
3 \cdot 6 \\
3 \cdot 8 \\
0 \cdot 2 \\
6 \cdot 3 \\
4 \cdot 5 \\
324 \cdot 4 \\
39 \cdot 0 \\
30 \cdot 1 \\
35 \cdot 1 \\
5 \cdot 8 \%\end{array}$ & $\begin{array}{l}0.87 \\
0.92 \\
1.10 \\
0.67 \\
0.93 \\
0.85 \\
0.82 \\
0.76 \\
1.66 \\
1.32 \\
8.26 \\
0.95 \\
1.54 \\
0.78 \\
0.54 \\
0.76 \\
0.85\end{array}$ & $\begin{array}{ll}\left(\begin{array}{ll}0.80, & 0.95\end{array}\right) \\
\left(\begin{array}{ll}0.76, & 1.09\end{array}\right) \\
0.30, & 2.83) \\
0.18, & 1.71 \\
0.52, & 1.53 \\
0.63, & 1.13) \\
0.59, & 1.11) \\
0.15, & 2.21) \\
0.61, & 3.62) \\
0.43, & 3.08) \\
0.93, & 29.83) \\
0.35, & 2.07) \\
0.62, & 3.18) \\
0.68, & 0.88 \\
0.33, & 0.82 \\
0.48, & 1.15) \\
0.58, & 1.22)\end{array}$ \\
\hline
\end{tabular}

*Based on United States national rates. 
Table 5 Ratios of observed to expected deaths* for respiratory cancer for exposed (high and low) and unexposed categories according to specific age and work characteristics

\begin{tabular}{|c|c|c|c|c|c|}
\hline \multirow[t]{2}{*}{ Characteristic } & \multirow[t]{2}{*}{ Category (years) } & \multicolumn{2}{|c|}{ Exposed } & \multicolumn{2}{|c|}{ Unexposed } \\
\hline & & $O / E \dagger$ & $(O b s)$ & $O / E$ & (Obs) \\
\hline $\begin{array}{l}\text { Age started work } \\
\text { Year started work } \\
\text { Year worked } \\
\text { Age at death } \\
\text { Year of death } \\
\text { All respiratory cancer }\end{array}$ & $\begin{array}{l}<30 \\
\geqslant 30 \\
<1945 \\
\geqslant 1945 \\
<25 \\
\geqslant 25 \\
<60 \\
\geqslant 60 \\
<1975 \\
\geqslant 1975\end{array}$ & $\begin{array}{l}0.70 \\
1.15 \\
0.93 \\
0.98 \\
0.79 \\
0.98 \\
1.25 \\
0.92 \\
1.19 \\
0.65 \\
0.94\end{array}$ & $\begin{array}{l}(12) \\
(23) \\
(25) \\
(10) \\
(6) \\
(29) \\
(10) \\
(25) \\
(24) \\
(11) \\
(35)\end{array}$ & $\begin{array}{l}0.44 \\
0.85 \\
0.64 \\
0.82 \\
0.71 \\
0.67 \\
0.92 \\
0.59 \\
0.78 \\
0.56 \\
0.68\end{array}$ & $\begin{array}{l}(3) \\
(8) \\
(8) \\
(3) \\
(2) \\
(9) \\
(4) \\
(7) \\
(7) \\
(4) \\
(11)\end{array}$ \\
\hline
\end{tabular}

*One death due to respiratory cancer in a subject with undefined diesel exposure, not included in this table.

$\dagger \mathrm{O} / \mathrm{E}=$ Observed cases/expected cases.

Table 6 Directly standardised rate ratios comparing rates of respiratory cancer in exposed and unexposed subjects. The overall rate ratio $(1.42 \pm 0.497)$ is not significantly different from equality

\begin{tabular}{|c|c|c|c|c|}
\hline \multirow[t]{2}{*}{ Characteristic } & \multirow[t]{2}{*}{ Category (years) } & \multicolumn{2}{|l|}{ Diesel } & \multirow[t]{2}{*}{ Rate ratio } \\
\hline & & Exposed & Unexposed & \\
\hline $\begin{array}{l}\text { Age at death } \\
\text { Year of death } \\
\text { Overall }\end{array}$ & $\begin{aligned}< & 60 \\
\geqslant & 60 \\
& 1965-9 \\
& 1970-4 \\
& 1974-9\end{aligned}$ & $\begin{array}{r}0.975 \\
3.453 \\
1.093 \\
2.545 \\
1.675 \\
1.877 \\
\pm 0.319\end{array}$ & $\begin{array}{r}1.207 \\
1.730 \\
0.834 \\
1.719 \\
1.229 \\
1.325 \\
\pm 0.407\end{array}$ & $\begin{array}{c}0.81 \\
2 \cdot 00 \\
1.31 \\
1.48 \\
1.36 \\
1.42 \\
\pm 0.497\end{array}$ \\
\hline
\end{tabular}

${ }^{*}$ Rates ( $\times 1000$ person-years). Rates mutually standardised to five year age-calendar year distribution of the entire cohort.

curves in the life table represent the risk of dying from respiratory cancer during the follow up period for the diesel exposed and unexposed subjects older and younger than the mean age of the cohort. In workers above the mean age of 53.6 years in 1967 there was divergence in the survival curves with a greater risk of death (lower survival function) from respiratory cancer in the group exposed to diesel. There were few deaths from respiratory cancer in those aged under 53.6 in 1967, and no difference was observed in the survival curves.
The Cox Proportional Hazards Model confirmed, as expected, that age was a strong independent risk factor for respiratory cancer (table 7). A 64 year old subject in 1967 had a risk of dying from lung cancer during the follow up period approximately nine times greater than someone aged 45 . The year a subject started work did not significantly contribute to the model $(p>0.05)$. The odds ratio for respiratory cancer in the low diesel exposure relative to the unexposed group was $1 \cdot 50$, and it was 2.77 for the high diesel exposed group relative to the unexposed

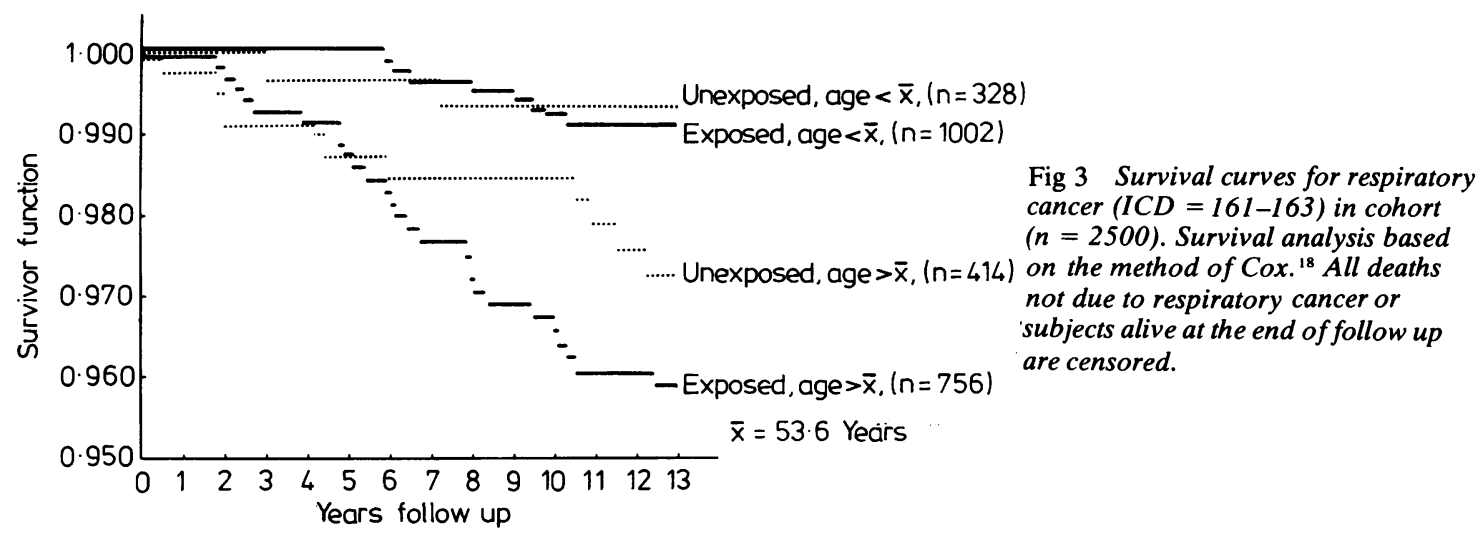


Table 7 Results of Cox Proportional Hazards Model for respiratory cancer $(I C D=161-163)$. Odds ratios are relative to the reference categories, which are assigned a value of 1.00 . The $p$ values are 2 tailed

\begin{tabular}{llll}
\hline & Coefficient Relative & $\begin{array}{c}\text { R (2-tailed) } \\
\text { risk }^{*}\end{array}$ & \\
\hline Age in 1967: & 0.1097 & & $<0.001$ \\
$\quad 45$ & & 0.39 & \\
$53.6(\mathrm{x})$ & 1.00 & \\
64 & & 3.11 & \\
& & \\
Diesel exposure in 1959 & 0.4079 & & 0.072 \\
$\quad$ (None) & & 1.00 & \\
1 (Low) & & 1.50 & \\
2.5 (High) & & 2.77 & \\
\hline
\end{tabular}

*Relative risk defined as the ratio of hazard functions.

workers. The $p$ value ( 2 tailed) for the diesel exposure variable $(\mathrm{p}=0.072)$ did not achieve conventional levels of statistical significance.

\section{Discussion}

This pilot study was designed to evaluate the feasibility of a larger retrospective cohort study and not to test the hypothesis that exposure to diesel may cause cancer. Despite the limited statistical power, the results are consistent with a weak association between diesel exposure and lung cancer. The directly standardised rate ratio for respiratory cancer among subjects exposed to diesel relative to the unexposed subjects was $1 \cdot 42 \pm 0 \cdot 50(\bar{x} \pm S E)$. A Cox Proportional Hazards Model confirmed the findings of the standardised rate ratio and also showed a greater risk of respiratory cancer with higher exposure to diesel. The increased risk of respiratory cancer in subjects exposed to diesel was not statistically significant, but the magnitude of the effect is in the range predicted by other studies. ${ }^{72}$

Potential sources of error must be considered in evaluating the results of this pilot study. The preliminary classifications of diesel exposures from job classifications may have been inaccurate, and may be modified by hygiene measurements now being made. If the misclassification resulted in random assignment of job categories to the incorrect diesel exposure, the result would be to reduce the power of the study but not to introduce a bias.

Another potential error is the incorrect assignment of individuals to a diesel exposure category based on their job history. Only a small percentage of subjects changed their exposure category between 1959 and 1967, and the changes were approximately equal in both directions. If switching from a diesel exposed to an unexposed category were due to the adverse health effects of the exposure the classification of exposure based on cumulative work history or on job exposure before retirement or death would introduce a bias. The effect of such a misclassification would be to make it more difficult to observe an association between exposure to diesel and lung cancer if one were present.

Only one case of respiratory cancer occurred in a subject whose exposure changed between 1959 and 1967. This subject began work with the railway in 1952 , and was a "labourer in the stores" (a low exposure occupation) from 1959 until 1965. In 1966 he became a motor vehicle operator, a job he continued until 1971, when he became a clerk for a single year before his death in 1972 . This case may reflect the switching of a symptomatic and less physically fit subject to a less exposed (and less strenuous job), as may occur in other industries. To avoid misclassification bias due to such transfers, we used job category in 1959 to classify subjects for this analysis.

A more serious bias would be caused by differences in cigarette smoking among the different exposure categories. We selected the cohort from job classifications of similar socioeconomic status, a known correlate of cigarette smoking habits. ${ }^{23}{ }^{24}$ Despite this selection, small differences in smoking between the exposed and unexposed subjects may have occurred by chance. We do not believe that such a difference explains the findings. It is possible to calculate an expected difference in lung cancer rates due to differences in smoking prevalence. ${ }^{25}$ Assuming that the relative risk of lung cancer from cigarette smoking is 10 , then a $5 \%$ greater prevalence of smoking in exposed subjects would be expected to produce an observed relative risk of 1.07 for lung cancer, and a $10 \%$ difference in smoking rate would yield a relative risk of only $1 \cdot 15$.

If workers exposed to diesel were also exposed to asbestos such an association would result in true confounding with attribution of lung cancer that was due to previous exposure to asbestos to diesel exposure. Asbestos was used on the railways to insulate steam engines and passenger cars, and several repair and maintenance jobs may have had significant exposure to asbestos. We are not, however, aware of any data indicating that operating personnel-for example, engineers - who comprise most of the low exposure group had exposure to airborne asbestos in steam or diesel locomotive cabs.

Exposure to asbestos by some repair personnel (such as mechanics) may in part explain the observed rate ratio of 2.77 for respiratory cancer among the high diesel exposed group in the current study. Further study of this question in the large cohort study will include evaluation of the incidence of mesothelioma, a marker of exposure to asbestos. ${ }^{26} \mathrm{We}$ are also collecting data on current and historical exposures to asbestos among railway 
workers.

Several early epidemiological studies of railway workers failed to consider the latent period for lung cancer, and thus reflected exposures that occurred before the introduction of diesel engines. ${ }^{82728}$ The best epidemiological study on diesel exposure and lung cancer is the recently completed London Transport workers study by Waller. ${ }^{29}$ This study began as a general evaluation of occupational health in male London Transport workers aged 45 to 64 . Subsequently, deaths from lung cancer occurring while in service were ascertained and mortality ratios determined for the period 1950 to 1974 in occupational categories with different presumed exposure to diesel exhaust. Whereas the observed number of cases of lung cancer in all occupational groups was below the expected number, based on age specific lung cancer death rates for Greater London, a gradient was seen with higher SMRs in the highest exposure group. The rate of lung cancer in the highest exposure category was approximately $20 \%$ greater than in the unexposed workers, but the difference was not statistically significant.

The London Transport workers study has several weaknesses. Lung cancers occurring after a worker left the London Transport Authority service were not recorded. During the study a large number of West Indian and Asian workers began service with the LTA, and there was no adjustment for their distribution in the work force. Differences in ethnic or social class composition and cigarette smoking may have existed between the unexposed engineers and the exposed operating and maintenance personnel.

Despite these limitations, Waller's study has been extensively analysed and has been used as the major source for risk estimates of lung cancer due to ambient concentrations of diesel exhaust. ${ }^{22}$ In view of the limited data on which these estimates have been made, further epidemiological studies of this question are indicated.

The results of this pilot study of railway workers are consistent with a small increase in the risk of respiratory cancer in diesel exposed occupations. The directly standardised risk of respiratory cancer in diesel exposed workers relative to unexposed workers was 1.42 , or a $42 \%$ increase, but was not statistically significant. The magnitude of the overall increased risk may also have been confounded by exposure to asbestos among the highest diesel exposure categories, but an increase in the rate of respiratory cancer was also noted in the subjects with low exposure to diesel. We are now conducting a larger retrospective cohort and a case-control study to test this hypothesis with adequate statistical power and to assess further the possible effects of confounding exposures.
This work was supported in part by an Environmental Protection Agency Grant No R807515, National Heart Lung and Blood Institute Training Grants HL-05998 and HL-07427, National Institute of Environmental Health Sciences National Individual Research Award ES-05157, NIH Center Grant 5-POES02109, and NIEHS Center Grant 5-POES00002-20.

\section{References}

' National Research Council. Health effects of exposure to diesel exhaust. Washington: National Academy Press, 1981.

${ }^{2}$ Environmental Protection Agency. Health effects of diesel engine emissions: proceedings of an international symposium, 1980. Cincinnati, Ohio: EPA, 1980. (EPA-600/9-80:057a.)

${ }^{3}$ Lewtas J, ed. Toxicological effects of emissions from diesel engines. New York: Elsevier North Holland, Inc, 1981.

${ }^{4}$ Santodonato J, Basu D, Howard P. Health effects associated with diesel exhaust emissions. Cincinnati, Ohio: EPA, 1978. (EPA-600/1-78-063.)

${ }^{5}$ Briggs T, Throgmorton J, Karaffa M. Air quality assessment of particulate emissions from diesel powered vehicles. Cincinnati, Ohio: EPA, 1978. (EPA-450/3:78-038.)

- Environmental Health Associates, Inc. Health effects of diesel exhaust emissions: a report prepared for the American Mining Congress. Berkeley, CA: 1978.

' Schenker MB. Diesel exhaust, an occupational carcinogen? JOM 1980;22:41-6.

${ }^{8}$ Schenker MB, Speizer FE. A retrospective cohort study of diesel exhaust exposure in railroad workers: study design and methodologic issues. In: Pepelko WE, Danner RB, Clark NA, eds. Health effects of diesel engine emissions. Cincinnati, Ohio: Environmental Protection Agency, 1979;1114-26. (EPA600/9-80-057b.)

${ }^{9}$ Claxton LD. Mutagenic and carcinogenic potency of diesel and related environmental emissions: Salmonella bioassay. Environment International 1981;5:389-91.

${ }^{10}$ Mitchell AD, Evans EL, Jotz MM. Mutagenic and carcinogenic potency of extracts of diesel and related environmental emissions: in vitro mutagenesis and DNA damage. Environment International 1981;5:393-401.

" Casto BC, Hatch GC, Huang SL, Lewtas J, Nesnow S, Waters MD. Mutagenic and carcinogenic potency of extracts of diesel and related environmental emissions: in vitro mutagenesis and oncogenic transformation. Environment International 1981;5:403-9.

12 McClellan RO, Brooks AL, Cuddihy RG, Jones RK, Manderly JL, Wolff RK. Inhalation toxicology of diesel exhaust particles. In: Lewtas J, ed. Toxicologic effects of emissions from diesel engines. New York: Elsevier North Holland, Inc, 1981.

${ }^{13}$ United States Interstate Commerce Commission. Rules governing the classification of railroad employees. Washington; USICC 1951.

${ }^{14}$ United States Department of Labor. Dictionary of occupational title. Washington; DOL 1977.

is Hobbs JR, Walter RA, Hard T, et al. Train generated air contaminants in the train crew working environment. Washington: United States Department of Transportation, 1977. (FRA/ ORD-77/08.)

${ }^{16}$ Peay A, Sanders B. Health and safety implications of diesel locomotive emissions. Washington: Department of Transportation 1978. (FRA report 78/18.)

${ }^{17}$ Monson RR. Analysis of relative survival and proportional mortality. Computer and Biomedical Research 1974;7:325-32.

${ }^{18}$ Kaplan EL, Meier P. Nonparametric estimation from incomplete observations. Journal of American Statistical Association 1958;53:457-81. 
${ }^{19}$ Cox DR. Regression models and life-tables. Journal of Royal Statistical Society 1972;B 34:187-202.

${ }^{20}$ Dixon WJ, ed. BMDP statistical software. 1981 ed. Los Angeles; University of California Press, 1981.

${ }^{21}$ United States Railroad Retirement Board. Occupational differences in separation rates for railroad workers, 1971-74. Chicago; USRRB, 1977.

${ }^{22}$ Harris JE. Potential risk of lung cancer from diesel engine emissions. Report to the National Research Council, National Academy Press. Washington; 1981.

${ }^{23}$ Sterling TD, Weinham JJ. Smoking patterns by occupation, industry, sex and race. Arch Environ Health 1981;36:313-7.

${ }^{24}$ Fox AJ, Adelstein AM. Occupational mortality: work or way of life? J Epidemiol Community Health 1978;32:73-8.

${ }^{25}$ Axelson $\mathrm{O}$. Aspects of confounding and effect modification in the assessment of occupational cancer risk. $J$ Toxic Environ
Health 1980;6:1127-31.

${ }^{26}$ McDonald JC, McDonald AD. Mesothelioma as an index of asbestos impact. In: Peto R, Schneiderman M, eds. Banbury report 9. Quantification of occupational cancer. New York: Cold Spring Harbor Laboratory, 1981;73-85.

${ }^{27}$ Kaplan I. Relationship of noxious gases to carcinoma of the lung in railroad workers. JAMA 1959;171:2039-43.

${ }^{28}$ Hueper WC. A quest into the environmental causes of carcinoma of the lung. Public health monograph No 36. Washington: United States Department of Health, Education and Welfare, 1955.

${ }^{29}$ Waller RE. Trends in lung cancer in London in relation to exposure to diesel fumes. In: Pepelko WE, Danner RM, Clark NA, eds. Health effects of diesel engine emissions. Cincinnati, Ohio: Environmental Protection Agency, 1979:1085-99. (EPA-600/9-80-057b.) 